\title{
Barriers to cervical cancer screening in Guatemala: a quantitative analysis using data from the Guatemala Demographic and Health Surveys
}

\author{
Anna Gottschlich ${ }^{1} \cdot$ Pamela Ochoa $^{2} \cdot$ Alvaro Rivera-Andrade $^{3} \cdot$ Christian S. Alvarez $^{1,4} \cdot$ Carlos Mendoza Montano $^{3}$. \\ Claudia Camel $^{5} \cdot$ Rafael Meza $^{1}$
}

Received: 8 July 2019/Revised: 21 November 2019/Accepted: 2 December 2019/Published online: 14 December 2019

(C) The Author(s) 2019

\begin{abstract}
Objectives Examine the association between commonly reported barriers to health care, including discordant spoken languages between patients and providers, and reported previous cervical cancer screening.

Methods Data from the nationally representative Guatemala National Maternal and Child Health Survey from the Demographic and Health Surveys Program were used to explore associations between barriers and screening rates nationwide and in high-risk populations, such as rural and indigenous communities. Negative binomial regressions were run accounting for survey sample weights to calculate prevalence ratios.

Results $64.0 \%, 57.5 \%$ and $47.5 \%$ of women reported ever screening, in the overall, indigenous, and rural populations, respectively. Overall, never screened for cervical cancer was associated with the following health barriers: needing permission, cost, distance, not wanting to go alone, and primary language not spoken by health providers, even after adjustment for age, ethnicity, and literacy.

Conclusions Offering screening programs alone is not enough to reduce the burden of cervical cancer in Guatemala. Measures need to be taken to reduce barriers to health care, particularly in rural areas, where screening rates are lowest.
\end{abstract}

Keywords Cervical cancer $\cdot$ Screening $\cdot$ Healthcare barriers · Indigenous communities

\section{Introduction}

Electronic supplementary material The online version of this article (https://doi.org/10.1007/s00038-019-01319-9) contains supplementary material, which is available to authorized users.

Rafael Meza

rmeza@umich.edu

Anna Gottschlich

annagott@umich.edu

Pamela Ochoa

dpamela.ochoa@gmail.com

Alvaro Rivera-Andrade

ariveraandrade@gmail.com

Christian S. Alvarez

calvrez@umich.edu

Carlos Mendoza Montano

cmendoza@incap.int
Cervical cancer is the fourth most commonly diagnosed cancer in women worldwide, with $85 \%$ of cases in low- and middle-income countries (LMICs) (Jemal et al. 2010). The

Claudia Camel

claucamelpnsr@gmail.com

1 Department of Epidemiology, School of Public Health, University of Michigan, Ann Arbor, MI, USA

2 PRA Health Sciences, Guatemala City, Guatemala

3 Research Center for the Prevention of Chronic Diseases, Institute of Nutrition of Central America and PanamaINCAP, Guatemala City, Guatemala

4 Division of Cancer Epidemiology and Genetics, National Cancer Institute, Bethesda, MD, USA

5 Guatemala Ministry of Health and Social Assistance (MSPAS), Guatemala City, Guatemala 
burden of this disease differs vastly between LMICs and high-income countries (HICs), where rates of cervical cancer are low. In Central America, cervical cancer is the second most common cause of cancer death in women (Soneji and Fukui 2013; Ferlay et al. 2019), and in Guatemala rates of cervical cancer mortality are six times that in the USA (ASMRs: 11.7 death vs. 1.9 deaths per 100,000 person-years, respectively) (International Agency for Research on Cancer 2018). This discrepancy begs the question of why women are dying from a disease that is mostly avoidable through screening practices commonly and effectively implemented in HICs.

Latin American countries experience many challenges that directly affect mortality rates from cervical cancer. Screening rates remain low, even in countries with national screening programs, perhaps due to cultural, logistical, and cost barriers (Soneji and Fukui 2013). Additionally, limited supply of highly trained healthcare providers and laboratory technicians, insufficient evaluation and follow-up of results, and lacking availability of access to screening contribute to low rates, limiting progress in the reduction of cervical cancer (Soneji and Fukui 2013). Fragmented health systems cause delays in diagnostic workup, often resulting in advanced tumors that necessitate expensive diagnostic procedures and treatments (Strasser-Weippl et al. 2015), which are not readily available. Finally, access to high-cost drugs and implementation of novel early detection and treatment technologies is limited.

The Ministry of Health $(\mathrm{MOH})$ of Guatemala has worked to implement effective screening and treatment programs since the 1950s, and the National Reproductive Health Program (PNSR) has been strengthening the training and infrastructure for these programs since its creation in 2000 (Ministerio de Salud Pública y Asistencia Social 2014). According to the $\mathrm{MOH}$, the public health system in Guatemala has 27 cytology laboratories, 7 pathologists, 21 cytotechnologists, 32 colposcopes, 33 cryotherapy units, 9 thermocoagulation units, and 11 electrosurgery units (de León et al. 2014; Ministerio de Salud Pública y Asistencia Social 2014; Camel 2018). However, even with infrastructure in place, studies show that less than half of women in Guatemala report ever been screened for cervical cancer (Chary and Rohloff 2014). In Guatemala, free health care is a constitutional right, and the $\mathrm{MOH}$ offers screening at no cost (Chary and Rohloff 2014). However, annual screening coverage by the $\mathrm{MOH}$ is only $12-18 \%$, while total screening coverage is around 40\% (Chary and Rohloff 2014). The World Health Organization recommends $80 \%$ coverage for successful national screening programs (Ferlay et al. 2012). Women also have challenges receiving screening results and accessing follow-up care (Holme et al. 2017; Austad et al. 2018; Im et al. 2018), and, in some cases, the quality and sensitivity of Pap smears have been called into question (Im et al. 2018).
Lack of access to screening in LMICs is a main reason for higher rates of cervical cancer (Austad et al. 2018; Im et al. 2018). Several studies have assessed barriers to cervical cancer screening in the USA, England, Serbia, Mexico, and other parts of Latin America (Lee 2000; Watkins et al. 2002; Agurto et al. 2004; Markovic et al. 2005; Waller et al. 2009). Barriers to screening include practical factors such lack of knowledge (Agurto et al. 2004; Markovic et al. 2005; Andreassen et al. 2018), prohibitive costs (Lee 2000), and difficulty accessing the healthcare system (Lee 2000; Watkins et al. 2002; Agurto et al. 2004; Markovic et al. 2005; Waller et al. 2009), as well as emotional factors such as embarrassment (Lee 2000; Watkins et al. 2002; Agurto et al. 2004), fear of pain (Lee 2000; Agurto et al. 2004), and socio-cultural health beliefs (Lee 2000; Watkins et al. 2002). In response to these, increases in screening education, taking into account cultural beliefs and local context, and increased accessibility to health services have been proposed.

However, there have been few screening barrier studies in primarily indigenous populations (Chary and Rohloff 2014; Austad et al. 2018), who tend to be underserved in many aspects, including health care (Chary et al. 2017), and who constitute approximately half the population of Guatemala. Furthermore, there are 24 spoken languages in Guatemala (Ministerio de Salud Pública y Asistencia Social 2014), and it has been reported that lack of concordant languages spoken by communities and their doctors creates additional barriers to healthcare services (Avila et al. 2015). Yet, there is a gap in the literature exploring the association between discordant languages and participation in cervical cancer screening. To date, it remains unclear whether barriers to cervical screening for non-indigenous populations described above are similar among indigenous populations, who are disproportionately burdened by this disease. This paper used data from the 2014 to 2015 Guatemala National Maternal and Child Health Survey (ENSMI) (USAID 2018) to investigate factors associated with screening for cervical cancer in subpopulations throughout Guatemala. Specifically, we assessed the effect that access barriers to health care, including not speaking the same language as community health providers, have on the rates of ever and recent cervical cancer screening among the general, rural, and indigenous populations.

\section{Methods}

\section{Data}

ENSMI is a nationally representative cross sectionally designed survey, carried out within the framework of the USAID Demographic and Health Surveys (DHS) program. 
The main purpose of the DHS program is to assist countries in developing, implementing, and analyzing nationally representative household surveys that provide data on population and health indicators. DHS provided technical assistance, supplies, and equipment to support ENSMI, which was implemented by the Institute of Nutrition for Central American and Panama (INCAP) (MSPAS et al. 2017). Further references to the survey will use "DHS/ ENSMI" to avoid confusion.

The most recent fieldwork went from October 2014 to June 2015. The National Institute of Statistics (INE) used a multi-stage stratified selection procedure in which approximately 36 sectors were selected randomly (proportionate to the overall number of urban and rural sectors defined by INE) from each of Guatemala's 22 departments. Then, approximately 26 homes were selected in each sector, creating a sample from the frame of the entire country that can be reasonably assumed as representative at the national, residential (urban vs rural) and regional (department) levels. Of the 22,308 households selected for participation, 21,383 (95.9\%) were successfully recruited, and from these, 25,914 women and 11,145 men responded to the survey. Female and male participants were 15-49 and 15-59 years old, respectively (USAID 2018).

\section{Variable creation}

The complete dataset was analyzed, representative of the entire country, and then restricted to rural and indigenous populations. DHS/ENSMI recorded participants as residing in rural or urban areas according to criteria defined by INE (Instituto Nacional de Estadistica 2011). In this classification, each department has both rural and urban areas. To create the rural subpopulation, we included persons living in rural areas of any department, while persons living in urban areas were excluded. The DHS/ENSMI asked participants to define their ethnicity, given the following choices: Ladino (persons of mixed ancestry), Maya (persons of indigenous descent), Xinca (persons of indigenous descent), Garifuna (persons of Afro-Caribbean descent), or other. Other counts were less than $1 \%$ of the data and thus were dropped from analyses. To create the indigenous subpopulation, we included persons who responded that they were either Maya, Garifuna, or Xinca, and excluded Ladinos. Survey sampling weights, available from DHS, were used in all analyses. Finally, analyses were subset to women in the age range of 25-49 to attempt to mimic both the Guatemalan National Guide for Testing and Treating Precancerous Lesions to Prevent Cervical Cancer (de León et al. 2014) and the National Cancer Prevention Plan (Ministerio de Salud Pública y Asistencia Social 2014) guidelines, which both recommend cervical cancer screening for women ages 25-54. Unfortunately, DHS/
ENSMI does not survey women over the age of 49, and so we were unable to assess women in the 50-54 age range. While only women who have been sexually active are at risk for cervical cancer, we decided to include all women in this age range, because neither guideline excludes those with no sexual history, and since sexual history is selfreported.

The main outcome explored was prior cervical cancer screening. We defined this as screening that was understood and remembered by the woman receiving it. Thus, women who responded "No" to having heard of cervical cancer or screening were included in the "Never Screened" group, even though they were not directly asked the follow-up question about ever been screened. Women who responded "Yes" to having heard of cervical cancer or screening and then "No" to ever screening were also included in the "Never Screened" group. Finally, women who responded "Yes" to both having heard of cervical cancer or screening and to prior screening were included in the "Ever Screened" group. USAID's Health Finance and Governance project used a similar definition in their 2015 Health Systems Assessment Report, including those who had never heard of screening in the "Never Screened" group (Avila et al. 2015). This binary ever-screened variable was used as an outcome to investigate predictors and barriers to screening across subpopulations.

According to both previously mentioned screening guidelines, (de León et al. 2014; Ministerio de Salud Pública y Asistencia Social 2014), women with a prior negative screen should continue cytological screening approximately every three years. Thus, we also explored prevalence of screening within this timeframe, to measure compliance with frequency recommendations. The survey asked women their current age as well as age at last Pap. Using this data, we created an indicator to identify cervical cancer screening in the past three years. The percent of "up-to-date" women across population groups were then calculated and compared to the percent of women reporting ever-screening.

Predictor variables explored included potential barriers to screening. The DHS/ENSMI asked women about perceived barriers to health care. These barriers included needing permission from family to access care, the cost of the care, the distance to the facility, and not having anyone to travel with to a facility. Each barrier was constructed as a binary variable (yes/no). Additionally, we created a language barrier variable as a potential predictor. The DHS/ ENSMI asked women the primary language spoken in their home and what languages were spoken by health professionals in local facilities. A binary variable was created to identify if there was a match between the participant's primary language and any language spoken at local facilities. 
Finally, age, ethnicity, and education (none, primary, secondary, or higher) were used to adjust regression models. Other demographic variables were explored to compare women with prior screening to those with no screening, including a wealth index developed by the DHS. This index is produced from a score created using interviewer-observed household characteristics (such as material of the house, source of water, number of people per room, and electronic items in the house) and is thus less susceptible to responder misclassification than self-reported variables such as income and education (MSPAS et al. 2017).

Missingness was less than $0.05 \%$ for all variables used in analyses.

\section{Statistical analyses}

Women with prior screening were compared to those with none, and binary and categorical variables were compared using proportion and Chi-square tests, respectively. Continuous variables were tested using a $t$ test to compare means. Alpha was set at 0.05, and unweighted count, percentage of subgroup, standard deviation, and $p$ value are shown in relevant tables.

Additionally, prevalence ratios of never screened were modeled using multivariate negative binomial regression with robust variance using reported barriers to health care, including language, as predictors. Crude models were adjusted for age, ethnicity, and education: factors previously shown in the literature to be associated with screening (Soneji and Fukui 2013).

Sensitivity analyses were conducted to assess the impact of our definition of prior screening. First, models were rerun considering only those participants who had heard of screening and thus were explicitly asked whether they had previously screened. Then, models were rerun, subset to only those who reported prior sexual activity, and were thus truly at risk for cervical cancer according to their selfreported history.

Data cleaning and statistical analyses were conducted using the R statistical software version 3.4.4.

\section{Results}

The 2014-2015 DHS/ENSMI recruited 25,914 women of ages 15-49. Our analyses used data from the subset of 15,317 women of ages 25-49 (Guatemala $N=15,317$, Rural $N=8399$, Indigenous $N=5728)$. The weighted average age was approximately 36 years old across all populations. In the overall population, $63.7 \%$ of women reported prior screening. This number decreased in the rural and indigenous populations, with only $57.5 \%$ and $47.5 \%$ reporting prior screening, respectively (Table 1).

\section{Demographics}

Demographics, stratified by screening status, are shown in Table 1. Women who reported prior screening were older across populations (Guatemala: 36.38 vs $33.49, p<0.001$; Rural: 36.11 vs $33.38, p<0.001$; Indigenous: 36.49 vs 34.26, $p<0.001)$. Women in the overall and indigenous groups living in urban areas were more likely to have screened than those in rural areas, although this difference was smaller in the indigenous population (Guatemala: $52.16 \%$ vs $38.05 \%, p<0.001$; Indigenous: $35.41 \%$ vs $30.31 \%, p<0.001)$. Non-indigenous women in the overall and rural populations were more likely to have screened than indigenous, although again, the difference was smaller in the rural than overall population. Women with higher education, who were literate, and who were in higher wealth index quintiles were more likely to have screened across populations. In the rural and indigenous populations, there were overall fewer women with higher education and wealth, and fewer literate women. Finally, women who were currently or ever married were more likely than those who were not to report screening.

\section{Sexual and health history}

Women who reported prior screening also reported a younger age at sexual debut (Guatemala: 18.23 vs 18.79; Rural: 17.66 vs 18.39; Indigenous: 17.94 vs 18.36), a higher number of lifetime sexual partners (Guatemala: 1.56 vs 1.44; Rural: 1.36 vs 1.11; Indigenous: 1.34 vs 1.06 ), and more children than those who reported never screening (Table 2). When comparing all of Guatemala to rural and indigenous groups, more sexual partners were reported overall, but more children and younger ages for birth of first child were reported by rural and indigenous women. Women who reported visiting health facilities in the last year were more likely than those who did not to report screening (Guatemala: $72.89 \%$ vs $60.79 \%$; Rural: $75.21 \%$ vs $62.84 \%$; Indigenous: $73.00 \%$ vs $59.15 \%$ ). Across all populations, age at sexual debut was approximately 18 years old, similar to the rates in the USA (Centers for Disease Control and Prevention 2017), which has similar screening guidelines as Guatemala.

\section{Knowledge of cervical cancer}

Table 3 shows the distribution of knowledge of cervical cancer. Knowledge of cervical cancer is high across all populations but is lower among rural and indigenous women (overall 91.6\%, rural $87.8 \%$, indigenous $82.6 \%$ ). 


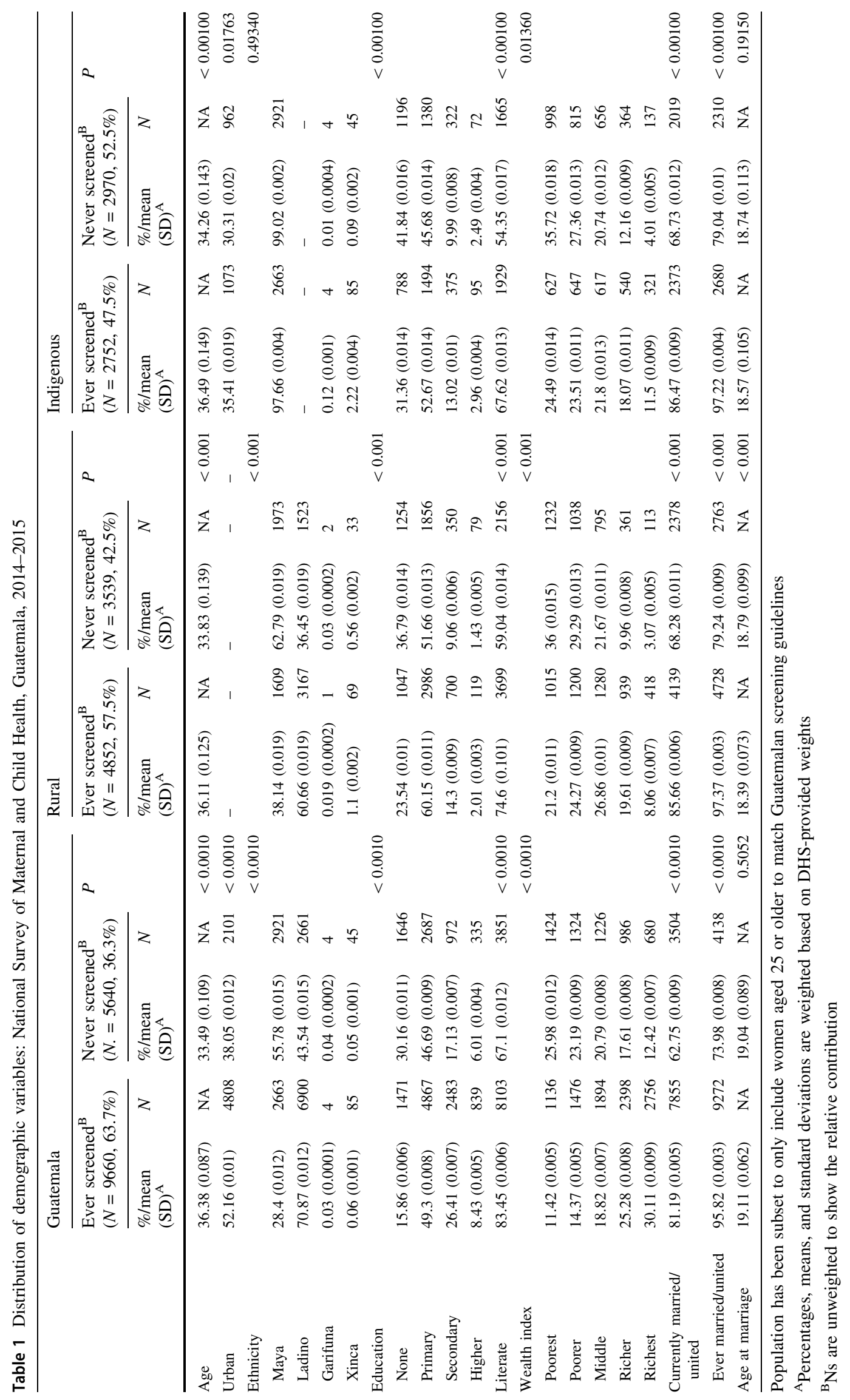




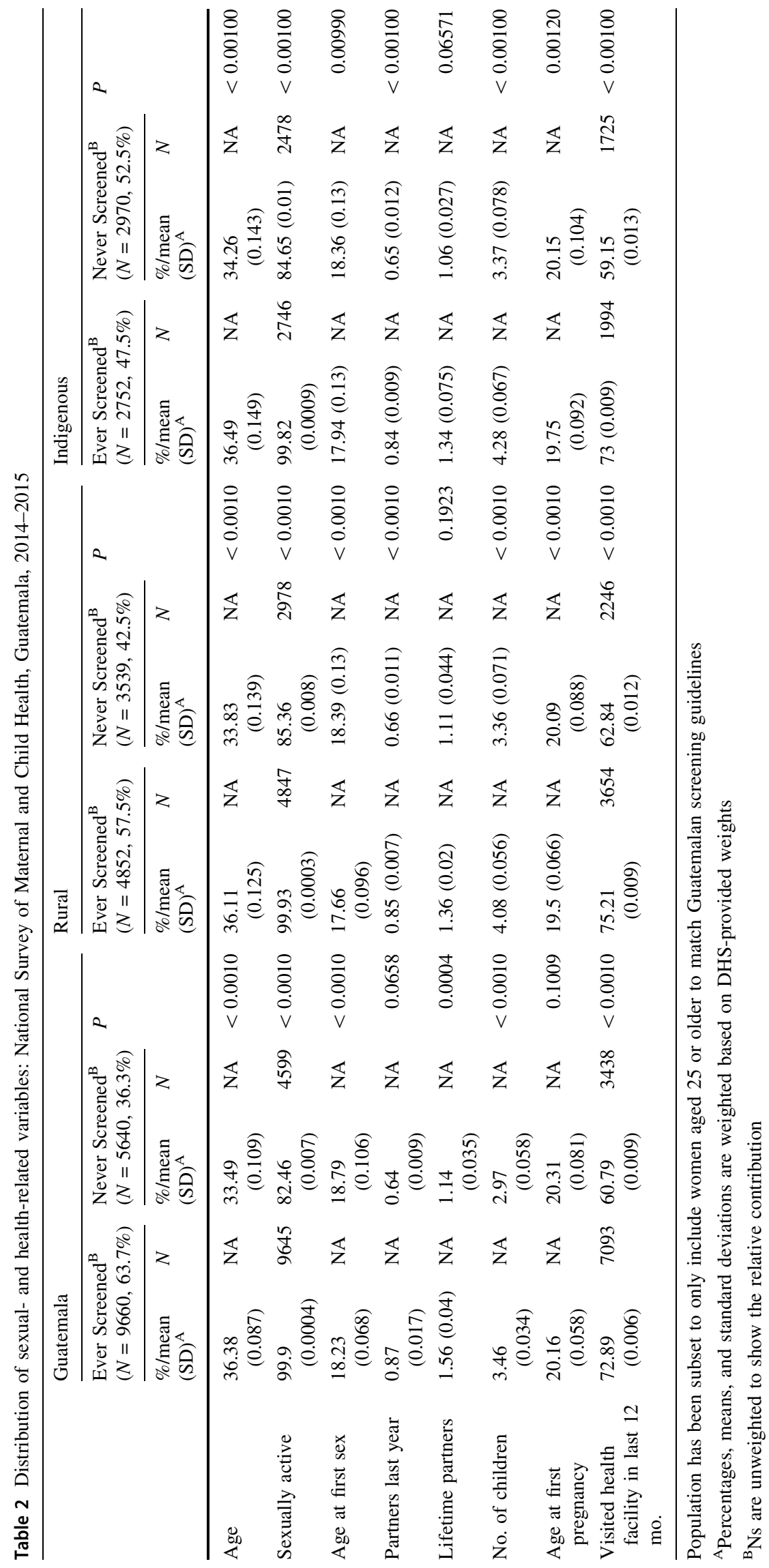


Among those who had heard of cervical cancer, those who had heard of screening were similarly high, but again lower among indigenous women.

Interestingly, women in the overall population who had heard of screening were more likely to have also received screening than women in the rural and indigenous populations (70\% overall, 66\% rural, 58\% indigenous) (Appendix Table A1).

\section{Screening}

As mentioned above, rates of prior screening were $47.5 \%$, $57.5 \%$ and $63.7 \%$ for the indigenous, rural, and overall populations, respectively. However, in the overall population, only $50.1 \%$ of women reported screening within the last three years (Table 3). In the rural and indigenous populations, the percent of women reporting screening within the last three years was even lower $(45.3 \%$ and $36.1 \%$ in the rural and indigenous populations, respectively).

\section{Barriers}

Across all populations, cost was the most reported barrier (over 60\% in each group reported cost as a barrier), followed by distance (over $35 \%$ in each group), not wanting to go alone, and finally needing permission (Table 4). Women who had never screened for cervical cancer were more likely to report each of the barriers across all populations (for example, in the overall population $60.8 \%$ reported cost as a barrier among screeners, while $67.5 \%$ of non-screeners reported this barrier). More women in the rural and indigenous populations reported barriers than in the overall population: needing permission was more common in the indigenous population than rural, while distance to the health facility was more common in the rural population than indigenous. Money and not wanting to go alone were similarly reported across the groups.

Women who had a doctor in their local health facility who spoke their primary language were statistically significantly more likely to have received screening than those who did not. Among indigenous women, of those who had ever screened, $64 \%$ had a doctor who spoke their primary language, while only $50 \%$ of women who had never screened had the same.

Results from multivariate analyses can be found in Table 5. The prevalence of prior screening was lower given any of the barriers, remaining significant, or nearly significant, even after adjustment for age, ethnicity, and education. Even though needing permission and not wanting to go alone were less commonly reported than money or distance, they were more strongly related to screening status. The prevalence of those who had never screened for women who reported needing permission in the overall population, the rural, and the indigenous subpopulation were 1.22 (95\% CI 1.15, 1.29), 1.21(95\% CI $1.13,1.30)$, and $1.18(95 \%$ CI $1.10,1.27)$ times that of women who did not report needing permission, respectively. Similarly, for not wanting to go alone, the prevalence of no prior screening was 1.22 (95\% CI 1.16, 1.28), 1.17 (95\% CI 1.10, 1.24), and 1.15 (95\% CI 1.08, 1.22) times that of women not reporting this barrier, respectively. The prevalence of no prior screening among women who did not have access to a doctor who spoke their primary language was between 1.19 and 1.25 times the prevalence than those who did, across populations.

The results of both sensitivity analyses are provided in the Appendix (Tables A2 and A3). Results from both analyses are consistent with our main analysis.

Table 3 Distribution of cervical cancer knowledge and prior screening variables: National Survey of Maternal and Child Health, Guatemala, 2014-2015

\begin{tabular}{|c|c|c|c|c|c|c|}
\hline & \multicolumn{2}{|c|}{ Guatemala $(N=15,317)$} & \multicolumn{2}{|c|}{ Rural $(N=8399)$} & \multicolumn{2}{|c|}{ Indigenous $(N=5728)$} \\
\hline & $\%(\mathrm{SD})^{\mathrm{A}}$ & $N^{\mathrm{B}}$ & $\%(\mathrm{SD})^{\mathrm{A}}$ & $N^{\mathrm{B}}$ & $\%(\mathrm{SD})^{\mathrm{A}}$ & $N^{\mathrm{B}}$ \\
\hline Heard of cervical cancer & $91.6(0.0047)$ & 14,036 & $87.8(0.0072)$ & 7422 & $82.6(0.0105)$ & 4750 \\
\hline If heard of $\mathrm{CC}$, heard of $\mathrm{CC}$ exam & $95.33(0.0025)$ & 13,409 & $94.59(0.0038)$ & 7060 & $92.5(0.0052)$ & 4414 \\
\hline If heard of CC, but not heard of CC exam, heard of Pap & $88.33(0.0146)$ & 545 & $84.5(0.0221)$ & 296 & $80.85(0.0244)$ & 263 \\
\hline Ever screened & $63.7(0.007)$ & 9660 & $57.5(0.01)$ & 4852 & $47.5(0.0114)$ & 2752 \\
\hline Screened past 3 years (among total population) & $50.0(0.007)$ & 7552 & $45.2(0.01)$ & 3803 & $36.1(0.0108)$ & 2098 \\
\hline
\end{tabular}

Population has been subset to only include women aged 25 or older to match Guatemalan screening guidelines

${ }^{A}$ Percentages and standard deviations are weighted based on DHS-provided weights

${ }^{\mathrm{B}} \mathrm{Ns}$ are unweighted to show the relative contribution 


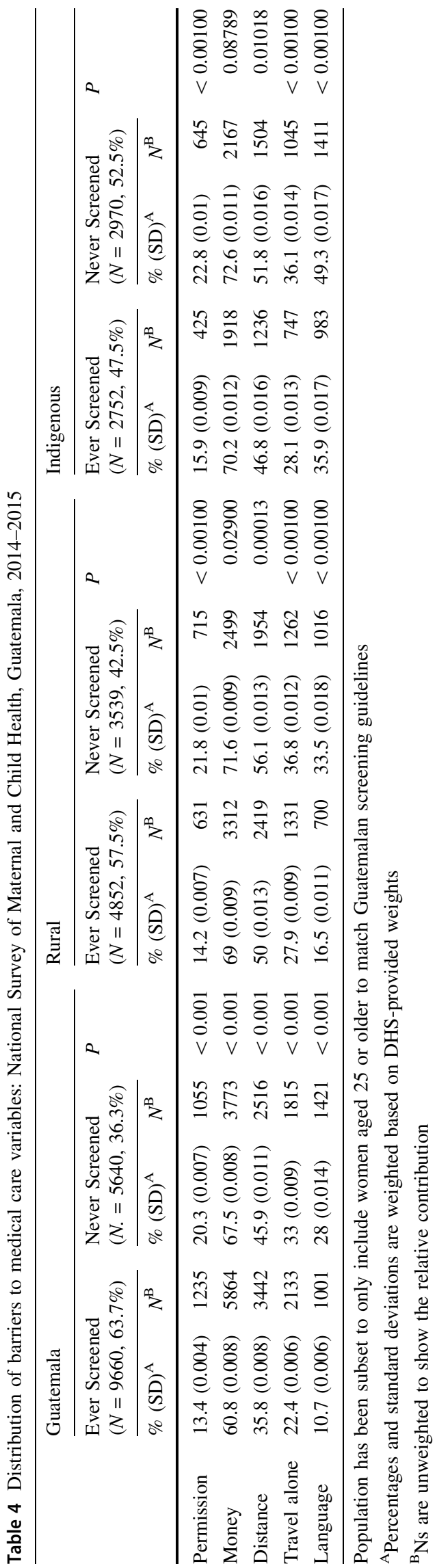

Discussion

This study has three important findings. First, there is a high rate of knowledge of cervical cancer and screening among women in Guatemala; however, rates of reported ever screening are still quite low. Women who are from rural or indigenous populations are less likely to have screened, even if they have heard of screening, than their country-wide counterparts. Compliance rates are even lower, and unfortunately recent screening has not increased meaningfully since the last Guatemalan DHS, conducted in 1999 (32.8\% report screening in the 2014-2015 survey versus 26.5\% in the 1999 survey) (Soneji and Fukui 2013). Thus, providing knowledge alone is clearly not sufficient to improve cervical cancer prevention in this setting. Second, reported barriers to health care, including needing permission, not having the required cost for care, not being able to travel the distance to health facilities, or not wanting to go alone, are significantly associated with no prior screening. These barriers need to be addressed to improve screening rates in Guatemala. Finally, women who do not speak the same language as their local health providers are less likely to have had screening. In countries like Guatemala, where many languages are spoken, additional efforts should be made to reduce language barriers in healthcare settings.

Additionally, our analyses showed that a variety of demographic factors are predictive of prior screening. Living in an urban area versus rural, identifying as nonindigenous versus indigenous, being literate and more highly educated, and being in a higher wealth index were all positively predictive of prior screening.

This study used the nationally representative Guatemala 2014-2015 DHS/ENSMI survey, which is the first DHS survey in Guatemala since the late 1990s. This dataset allows for a better understanding of accessibility (or lack thereof) of health care, and in particular as shown here, cervical cancer screening, among different populations around the country. The DHS is a long-standing and rigorous survey, with a larger sample size and more in-depth questionnaires than other smaller studies could manage. Thus, the DHS provides a reliable dataset for assessing screening access, which includes standard questions that are used in the same survey in other countries around the world.

However, this study has some limitations. The sampling design was based on the most recent Guatemalan census, which was conducted in 2002, a decade before survey planning began, leading to sampling decisions being made using 10-year-old data, which could lead to some biases as the urban population in Guatemala has been growing (Central Intelligence Agency 2019). Additionally, much of 
Table 5 Prevalence ratios of never prior cervical cancer screening: National Survey of Maternal and Child Health, Guatemala, 2014-2015

\begin{tabular}{|c|c|c|c|c|c|c|}
\hline & \multicolumn{2}{|c|}{ Guatemala } & \multicolumn{2}{|l|}{ Rural } & \multicolumn{2}{|c|}{ Indigenous } \\
\hline & PR & $95 \% \mathrm{CI}$ & PR & $95 \% \mathrm{CI}$ & PR & $95 \% \mathrm{CI}$ \\
\hline Permission & 1.22 & $1.15,1.29$ & 1.21 & $1.13,1.30$ & 1.18 & $1.10,1.27$ \\
\hline Money & 1.08 & $1.03,1.14$ & 1.04 & $0.98,1.11$ & 1.05 & $0.98,1.12$ \\
\hline Distance & 1.10 & $1.05,1.16$ & 1.09 & $1.02,1.16$ & 1.07 & $0.99,1.14$ \\
\hline Travel alone & 1.22 & $1.16,1.28$ & 1.17 & $1.10,1.24$ & 1.15 & $1.08,1.22$ \\
\hline Language & 1.23 & $1.16,1.31$ & 1.19 & $1.10,1.28$ & 1.25 & $1.18,1.32$ \\
\hline
\end{tabular}

Population has been subset to only include women aged 25 or older to match Guatemalan screening guidelines

Prevalence ratios modeled using multivariate negative binomial regression with robust variance

Models additionally adjusted for age, ethnicity (Maya, Ladino, Garifuna, Xinca), and education level (none, primary, secondary, higher)

Counts for each variable can be found in Table 4

the data used in these analyses are self-reported. As is recognized with reproductive care and healthcare access questions, there is a high possibility of misreporting, due to recall and desirability bias (Stuart and Grimes 2009; Gonsalves and Hindin 2017). For example, screening rates could either be over- or underestimated depending on whether there was a social desirability effect, which caused women to over-report screening, or a recall bias effect where women forgot or did not understand the meaning of getting screened, causing under-reporting. Finally, since participants self-reported the languages are spoken at clinics, we may be missing languages that participants were unaware were also spoken, although it is unlikely that they would not report their own. Independently, we believe that, despite this limitation, the correlation between perceived languages spoken and screening practices is an important finding in itself.

When the DHS released their final report of these data, they used all women from ages 15-49 to investigate access to cervical cancer screening. However, both Guatemala screening guidelines recommend that only women ages 25-54 should get screened for cervical cancer, and so we choose to only analyze women in this age group (truncated at age 49). Because of this, our reported screening and knowledge rates are slightly higher than those reported by the DHS because women ages 15-24 (who were excluded in our analyses) are generally not screened for and are less knowledgeable about cervical cancer (heard of Pap screening: $84.0 \%$ reported by DHS versus $88.3 \%$ reported in Table 3; prior screening, given knowledge of Pap: $49.8 \%$ reported by DHS and 69.9 reported in Table A1).

Many studies report ever-screened figures when discussing cervical cancer screening, but fewer look at up-todate screening, given country-specific recommendations. Our analyses showed, similar to other studies done in Guatemala (Murchland et al. 2019; Gottschlich et al. 2017), that around $60 \%$ of women report being screened for cervical cancer at some point in their life, however, as few as $40-50 \%$ are up-to-date on their screening.

With respect to barriers to health care, our findings are similar to the literature (Lee 2000; Watkins et al. 2002; Agurto et al. 2004; Markovic et al. 2005; Waller et al. 2009), even among the less commonly investigated indigenous populations. Other studies from Guatemala cite distance, cost, and lack of social support as barriers to accessing health care (Holme et al. 2017; Austad et al. 2018; Im et al. 2018). Similarly, this study found that cost and distance were the most commonly reported barriers to screening in all populations, including indigenous, and these, as well as needing permission and not wanted to go alone, were all statistically significantly associated with prior screening. These conclusions, along additional finding that language discordance is associated with lack of screening, can support practitioners and policy makers as they develop plans to improve cervical screening, and general healthcare delivery, in Guatemala.

Unfortunately, better access to screening programs alone is not enough to reduce the burden of cervical cancer in LMICs, like Guatemala. Additional studies are needed to understand the barriers and facilitators to not only getting screened, but also receiving the results of a screening test, and accessing any needed follow-up care and eventual treatment. Nonetheless, our study provides an updated assessment of the patterns of access to screening and the most salient barriers among highly at-risk groups in Guatemala, which is a critical step to evaluate the chain of events required for successful cervical cancer prevention programs.

Acknowledgements We would like to acknowledge the support received from the Organization of Women's Health and Development (ISDM) in Guatemala. Research reported in this publication was 
supported by the National Cancer Institutes of Health under Awards P30CA046592 and T32CA083654 (Gottschlich).

\section{Compliance with ethical standards}

Conflict of interest The authors declare that they have no conflict of interest.

Open Access This article is licensed under a Creative Commons Attribution 4.0 International License, which permits use, sharing, adaptation, distribution and reproduction in any medium or format, as long as you give appropriate credit to the original author(s) and the source, provide a link to the Creative Commons licence, and indicate if changes were made. The images or other third party material in this article are included in the article's Creative Commons licence, unless indicated otherwise in a credit line to the material. If material is not included in the article's Creative Commons licence and your intended use is not permitted by statutory regulation or exceeds the permitted use, you will need to obtain permission directly from the copyright holder. To view a copy of this licence, visit http://creativecommons. org/licenses/by/4.0/.

\section{References}

Agurto I, Bishop A, Sánchez G et al (2004) Perceived barriers and benefits to cervical cancer screening in Latin America. Prev Med (Baltim) 39:91-98. https://doi.org/10.1016/j.ypmed.2004.03.040

Andreassen T, Melnic A, Figueiredo R et al (2018) Attendance to cervical cancer screening among Roma and non-Roma women living in North-Western region of Romania. Int J Public Health 63:609-619. https://doi.org/10.1007/s00038-018-1107-5

Austad K, Chary A, Xocop SM et al (2018) Barriers to cervical cancer screening and the cervical cancer care continuum in rural Guatemala: a mixed-method analysis. J Glob Oncol. https://doi. org/10.1186/1471-2407-8-278

Avila C, Bright R, Gutierrez J et al (2015) Guatemala health system assessment, August 2015

Camel C (2018) Red de Servicios de Salud Para la Detección y Tratamiento de Cáncer Cervico Uterino del Ministerio de Salud Pública y Asistencia Social

Central Intelligence Agency (2019) Central America, Guatemala. CIA World Factb. https://www.cia.gov/library/publications/theworld-factbook/geos/gt.html. Accessed 17 Jul 2019

Centers for Disease Control and Prevention National Center for Health Statistics (2017) National Survey of Family Growth, Vital and Health Statistics. U.S. Department of Health and Human Services, Public Health Services. https://www.cdc.gov/ nchs/nsfg/key_statistics/s.htm\#vaginalsexual. Accessed $11 \mathrm{Sept}$ 2019

Chary AN, Rohloff PJ (2014) Major challenges to scale up of visual inspection-based cervical cancer prevention programs: the experience of Guatemalan NGOs. Glob Health Sci Pract 2:307-317. https://doi.org/10.9745/GHSP-D-14-00073

Chary A, Flood D, Austad K et al (2017) Accompanying indigenous Maya patients with complex medical needs: a patient navigation system in rural Guatemala. Healthcare. https://doi.org/10.1016/j. hjdsi.2017.08.006

de León LEM, Vila FFB, Bojórquez IL et al (2014) Guias Nacionales para el tamizaje y tratamiento de las lesiones precancerosas para la prevención del cáncer de cervicouterino

Ferlay J, Shin H, Bray F et al (2012) Cancer incidence and mortality Worldwide: IARC CancerBase No. 10
Ferlay J, Colombet M, Soerjomataram I et al (2019) Estimating the global cancer incidence and mortality in 2018: GLOBOCAN sources and methods. Int J Cancer 144:1941-1953. https://doi. org/10.1002/ijc.31937

Gonsalves L, Hindin MJ (2017) Pharmacy provision of sexual and reproductive health commodities to young people: a systematic literature review and synthesis of the evidence. Contraception 95:339-363. https://doi.org/10.1016/j.contraception.2016.12.002

Gottschlich A, Rivera-Andrade A, Grajeda E et al (2017) Acceptability of human papillomavirus self-sampling for cervical cancer screening in an indigenous community in Guatemala. J Glob Oncol JGO. https://doi.org/10.1200/jgo.2016.005629

Holme F, Kapambwe S, Nessa A et al (2017) Scaling up proven innovative cervical cancer screening strategies: challenges and opportunities in implementation at the population level in lowand lower-middle-income countries. Int $\mathrm{J}$ Gynecol Obstet 138:63-68. https://doi.org/10.1002/ijgo.12185

Im DD, Palazuelos L, Xu L et al (2018) A community-based approach to cervical cancer prevention: lessons learned in rural Guatemala. Prog Community Health Partnersh Res Educ Action 12:45-54. https://doi.org/10.1353/cpr.2018.0005

Instituto Nacional de Estadistica (2011) Encuesta nacional de condiciones de vida 2011

International Agency for Research on Cancer (2018) Global Cancer Observatory

Jemal A, Center MM, DeSantis C, Ward EM (2010) Global patterns of cancer incidence and mortality rates and trends. Cancer Epidemiol Biomark Prev 19:1893-1907. https://doi.org/10.1158/ 1055-9965.EPI-10-0437

Lee MC (2000) Knowledge barriers, and motivators related to cervical cancer screening among Korean-American women: a focus group approach. Cancer Nurs 23:168-175

Markovic M, Kesic V, Topic L, Matejic B (2005) Barriers to cervical cancer screening: a qualitative study with women in Serbia. Soc Sci Med 61:2528-2535. https://doi.org/10.1016/j.socscimed. 2005.05.001

Ministerio de Salud Pública y Asistencia Social (2014) Plan nacional de prevención, control y manejo de cáncer cervicouterino 2014-2024

MSPAS M de SP y AS, INE IN de E, Segeplan S de P y P de la P, DHS D and HS (2017) Encuesta Nacional de Salud Materno Infantil 2014-2015: Informe Final

Murchland AR, Gottschlich A, Bevilacqua K et al (2019) HPV selfsampling acceptability in rural and indigenous communities in Guatemala: a cross-sectional study. BMJ Open 9:1-12. https:// doi.org/10.1136/bmjopen-2019-029158

Soneji S, Fukui N (2013) Socioeconomic determinants of cervical cancer screening in Latin America. Rev Panam Salud Publica 33:174-182. https://doi.org/10.1158/0008-5472.CAN-10-4002.BONE

Strasser-Weippl K, Chavarri-Guerra Y, Villarreal-Garza C et al (2015) Progress and remaining challenges for cancer control in Latin America and the Caribbean. Lancet Oncol 16:1405-1438. https://doi.org/10.1016/S1470-2045(15)00218-1

Stuart GS, Grimes DA (2009) Social desirability bias in family planning studies: a neglected problem. Contraception 80:108-112. https://doi.org/10.1016/j.contraception.2009.02.009

USAID (2018) Demographic and Health Survey

Waller J, Bartoszek M, Marlow L, Wardle J (2009) Barriers to cervical cancer screening attendance in England: a population based survey. J Med Screen 16:199-204

Watkins MM, Gabali C, Winkleby M et al (2002) Barriers to cervical cancer screening in rural Mexico. Int J Gynecol Cancer 12:475-479

Publisher's Note Springer Nature remains neutral with regard to jurisdictional claims in published maps and institutional affiliations. 